\title{
Gripe A. Segundo acto. Adecuación de la solicitud de PCR para gripe A (H1N1) en un servicio de Urgencias
}

\author{
Influenza A. Act two. Suitability of request for PCR for \\ Influenza A (H1N1) in an emergency service department
}

\author{
J. Jacob ${ }^{1}$, E. Benavent ${ }^{1}$, F. Llopis ${ }^{1}$, C. Ferre ${ }^{1}$, J. Niubó ${ }^{2}$, I. Bardes ${ }^{1}$
}

\section{Sr. Director:}

Hemos leído con interés el editorial del Dr. Ò. Miró y A. Trilla publicado en el número 1 de 2011 en su revista ${ }^{1}$, y nos ha gustado especialmente el título elegido para dicha editorial, Gripe A (H1N1): segundo acto. En la línea del «segundo acto» de esta editorial, queríamos aportar nuestra experiencia, la de un hospital universitario de tercer nivel, con más de 900 camas de hospitalización. Tras la crisis sanitaria vivida en el invierno 2009-2010 debido a la aparición del nuevo virus de la gripe A (H1N1) ${ }^{2-4}$, que en ocasiones precipitó la solicitud indiscriminada de PCR para gripe A en los servicios de urgencias, derivada principalmente de la alarma social generada en los medios de comunicación, no sabíamos si en la campaña invernal 2010-2011 también se iba a dar esta situación, por lo que realizamos un análisis para conocer la adecuación en la solicitud de PCR para gripe A (H1N1) en urgencias, definida por la presencia de síndrome gripal en pacientes que requieren ingreso hospitalario por otro motivo (y por lo tanto se da la necesidad de realizar un aislamiento hospitalario), o bien por la presencia de síndrome gripal asociando insuficiencia respiratoria hipoxémica aguda $\left(\mathrm{Part} \mathrm{O}_{2}\right.$ inferior a $60 \mathrm{mmHg}$ ) o condensación pulmonar en la radiografía de tórax. Se realizó un análisis descriptivo y retrospectivo de 185 pruebas (correspondientes a 182 pacientes) de PCR para gripe A $(\mathrm{H} 1 \mathrm{~N} 1)$ realizadas en el servicio de urgencias del mes de octubre 2010 a marzo de 2011. Eran varones un $51,6 \%(\mathrm{n}=94)$ pacientes y la edad media fue de 58,7 (DS $\pm 17,6)$ años. De las 185 PCR que se solicitaron en urgencias encontramos: $19(10,3 \%)$ casos que precisaban ingreso por otro motivo y presentaban gripe, 85 $(46,2 \%)$ neumonía y gripe, 116 (63\%) insuficiencia respiratoria aguda hipoxémica y gripe. Se consideró que la solicitud de PCR era adecuada en 155 (83,8\%) solicitudes. De las 185 PCR solicitadas 72 (38,9\%) resultaron positivas, por lo que concluimos que la adecuación en la solicitud de PCR para gripe A (N1H1) en urgencias fue elevada y el porcentaje de PCR para gripe A (N1H1) positiva, también fue elevado. Estos datos nos confirman lo que los autores llaman en la editorial, "normalidad gripal recuperada" tras la situación inusual vivida el año 2009.

\section{An. Sist. Sanit. Navar. 2011; 34 (2): 293-294}

1. Servicio de Urgencias. Hospital Universitari de Bellvitge. L'Hospitalet de Llobregat.

2. Servicio de Microbiología. Hospital Universitari de Bellvitge. L'Hospitalet de Llobregat.

Recepción: 19 de mayo de 2011

Aceptación definitiva: 24 de mayo de 2011

\author{
Correspondencia \\ J. Jacob Rodríguez \\ Servicio de Urgencias \\ Hospital Universitari de Bellvitge \\ Feixa Llarga s/n \\ 08907 L'Hospitalet de Llobregat (Barcelona) \\ España \\ E-mail: 32229fjr@gmail.com
}




\section{BIBLIOGRAFÍA}

1. Miró Ò, Trilla A. Gripe A (H1N1): segundo acto. An Sist Sanit Navar 2011; 34: 1.

2. Vilella A, Trilla A. Gripe A (H1N1). Una nueva epidemia. Med Clin (Barc) 2009; 132: 783784.
3. Miró Ò. Una nueva gripe en un viejo escenario. Emergencias 2009; 21: 321-322.

4. Áluarez V, Merlo M, Cuesta MM, Ruiz MJ, Martín A, SILvIo J et al. Análisis del impacto y manejo de la pandemia de gripe A H1N1 en el servicio de urgencias de un hospital terciario. Emergencias 2010; 22: 181-186. 